\title{
Prevention of diseases after menopause
}

R. A. Lobo, S. R. Davis*, T. J. De Villiers ${ }^{\dagger}$, A. Gompel ${ }^{\ddagger}$, V. W. Henderson**, H. N. Hodis ${ }^{\dagger \dagger}$, M. A. Lumsden $^{\text {\#, W. J. Mack***, S. Shapiro }}{ }^{\dagger \dagger}$ and R. J. Baber ${ }^{\text {th }}$

Department of Obstetrics and Gynecology, Columbia University, New York, NY, USA; *School of Public Health and Preventive Medicine, Monash University, Melbourne, Australia; ${ }^{\dagger}$ Mediclinic Panorama and Department of Gynaecology, Faculty of Health Sciences, University of Stellenbosch, Cape Town, South Africa; 'UF de Gynécologie Endocrinienne, Université Paris Descartes, AP-HP, Hôpitaux Universitaires Paris Centre, Paris, France; **Departments of Health Research \& Policy (Epidemiology) and of Neurology \& Neurological Sciences, Stanford University, Stanford, CA, USA; ${ }^{\dagger}$ Atherosclerosis Research Unit, University of Southern California, Los Angeles, CA, USA;

HProfessor of Medical Education and Gynaecology, Clinical lead for Reproductive and Maternal Medicine, University of Glasgow, UK; ***Department of Preventive Medicine, University of Southern California, Los Angeles, CA, USA; ${ }^{\dagger \dagger}$ Department of Public Health and Family Medicine, University of Cape Town Medical School, Cape Town, South Africa; ${ }^{{ }^{+1}}$ Sydney Medical School, The University of Sydney, NSW, Australia

Key words: PREVENTION, MENOPAUSE, OBESITY, CARDIOVASCULAR, OSTEOPOROSIS, COGNITION, DEMENTIA, CANCER, HORMONAL THERAPY

Correspondence: Professor R. A. Lobo, Department of Obstetrics and Gynecology, Columbia University, New York, NY, USA; e-mail: ral35@columbia.edu

This paper was published in the October 2014 issue of Climacteric: Climacteric 2014;17:540-56

(c) 2014 International Menopause Society 


\begin{abstract}
Women may expect to spend more than a third of their lives after menopause. Beginning in the sixth decade, many chronic diseases will begin to emerge, which will affect both the quality and quantity of a woman's life. Thus, the onset of menopause heralds an opportunity for prevention strategies to improve the quality of life and enhance longevity. Obesity, metabolic syndrome and diabetes, cardiovascular disease, osteoporosis and osteoarthritis, cognitive decline, dementia and depression, and cancer are the major diseases of concern. Prevention strategies at menopause have to begin with screening and careful assessment for risk factors, which should also include molecular and genetic diagnostics, as these become available. Identification of certain risks will then allow directed therapy. Evidence-based prevention for the diseases noted above include lifestyle management, cessation of smoking, curtailing excessive alcohol consumption, a healthy diet and moderate exercise, as well as mentally stimulating activities. Although the most recent publications from the follow-up studies of the Women's Health Initiative do not recommend menopause hormonal therapy as a prevention strategy, these conclusions may not be fully valid for midlife women, on the basis of the existing data. For healthy women aged 50-59 years, estrogen therapy decreases coronary heart disease and all-cause mortality; this interpretation is entirely consistent with results from other randomized, controlled trials and observational studies. Thus. as part of a comprehensive strategy to prevent chronic disease after menopause, menopausal hormone therapy, particularly estrogen therapy may be considered as part of the armamentarium.
\end{abstract}

\title{
INTRODUCTION
}

As the world population increases, along with an increase in life expectancy, many millions of women will be spending a third or more of their lives after menopause. Several of the topics for World Menopause Day in the past have focused on treatment. This year, our focus is on Prevention. Indeed, from a medical economics perspective, although still debated, it is our view that preventing disease is much preferred over waiting to treat a condition once it manifests. Here we seek to outline the major chronic diseases that occur after menopause and suggest strategies that could be put in place to prevent these occurrences. Some of these conditions (cardiovascular disease) accelerate in women after menopause, and others (cancer) increase as a function of age in both men and women. Nevertheless, in the final analysis, our goal is to suggest strategies to combat all diseases after menopause with the aim of improving not only the quantity, but the quality of life for postmenopausal women world-wide. Women presenting to their medical providers during the menopausal transition provide a unique opportunity for risk assessment, counseling and the institution of various prevention measures.

Our perspective of happier and healthier women around the world is a lofty goal. We are cognizant that the prevalences of various diseases are different in various regions of the world, and therefore the emphasis for specific strategies will vary. Further, it is anticipated that, in the near future, we will 
have different tools for risk assessment, which will be personalized. Molecular tools and pharmacogenomics will enable us to determine individual risks and the appropriateness of various preventative therapies; some of these concepts will be explored later.

\section{EPIDEMIOLOGY OF CHRONIC DISEASES AFTER MENOPAUSE}

As noted above, life expectancy has increased in all areas of the world apart from Sub-Saharan Africa. This can be welcomed as the continuation of health and vigor allowing more years of work and an enjoyable retirement or it can be viewed with concern at the potential drain on the economy of those who are unfit and suffer from chronic disease. It is thus becoming a priority to investigate ways to improve health and well-being in all adults.

The age of the natural menopause among women in developed countries is between 50 and 52 years ${ }^{1,2}$ whereas, in the less developed countries, it is 3-4 years less ${ }^{3}$. Depletion of sex steroid hormones is an important consequence of normal aging and gonadal failure that potentially increases vulnerability to disease in hormone-responsive tissues, including the brain, bone and the cardiovascular system. Thus, early menopause is associated with an increased risk of cardiovascular disease (CVD) and osteoporosis, whereas delayed menopause is associated with increased risk of estrogen-dependent cancers such as endometrial and breast. After menopause, several chronic diseases may emerge, usually by the sixth decade, and these include obesity and metabolic disease, cardiovascular disease, osteoporosis and arthritis, dementia and cognitive decline, and cancer. An important opportunity exists at the onset of menopause to prevent or attenuate these chronic diseases which have an onset approximately 10 years later.

Obesity is a growing world-wide problem, which exacerbates many chronic disease states. In women, the altered distribution of fat that occurs at menopause leads to an increase in insulin resistance, and the incidence of diabetes has risen exponentially. This increase, in turn, translates into an increased risk of CVD and death, with the impact being greater in women than in men. It would seem logical that, if estrogen deprivation leads to altered fat distribution, it should be reversed by administration of estrogen replacement. Hormone therapy appears to decrease the incidence of diabetes and also improves diabetes control as indicated by assessment of glycosylated hemoglobin concentrations ${ }^{4,5}$ but has complex effects on levels of blood glucose itself, making the impact less certain ${ }^{6}$.

CVD is the most common cause of death in women, accounting for the greatest proportion of deaths over the age of 50 years. The overall prevalence of coronary heart disease (CHD) is estimated to be $5.1 \%$ in women compared with $7.9 \%$ in men, and the lifetime risk of developing CHD after 40 years of age is $32 \%$ in women and $49 \%$ in men; in addition, the incidence of CHD in women lags behind men by 10 years for CHD overall and by 20 years for myocardial infarction (MI) and sudden death. However, women generally face a worse prognosis than men following a primary event ${ }^{7}$. Within 5 years after a first MI, $18 \%$ of women and $8 \%$ of men aged 45-64 years develop heart failure. Older age at menopause is independently associated with a decreased risk of incident heart failure ${ }^{8}$. Prior studies have investigated the relationship between menopause and $\mathrm{CVD}^{9,10}$; however, the results have 
been inconsistent, and the direct causal relationship between menopause and increased cardiovascular risk is still being debated. Menopause before the age of 45 years is associated with increased risk ${ }^{10}$. Osteoporosis is a common disease which increases with age and predisposes to an increased risk of fractures $^{11}$. Up to $70 \%$ of women have osteoporosis of the hip, lumbar spine or distal forearm at the age of $80^{12}$. Other factors, such as low body mass index (BMI), tobacco, and alcohol, among others, may negatively influence bone density and strength, thereby increasing the risk of fracture ${ }^{13}$. Vertebral fractures account for almost half of all osteoporosis-related fractures ${ }^{14}$. Osteoporotic fracture is more common in women than men and causes considerable morbidity as well as indirect mortality due to problems relating to immobility. The number of osteoporotic fractures (hip and spine) is rising exponentially and this has a massive impact on the health services as well as the quality of life of the individual.

Arthritis is very common and osteoarthritis is an almost universal condition in the older patient. It may be caused by the 'wear and tear' of sport in youth or simply be a facet of aging and is undoubtedly worsened by obesity. Although weight loss may not impact on the process itself, it is likely to improve mobility. Inflammatory arthritis is more common in women but is associated more with younger age.

Dementia and cognitive decline are major concerns for women and society, and the number of women affected is rising globally as life expectancy increases. Today, about 36 million people world-wide suffer from Alzheimer's disease and other dementia. This figure is projected to more than double by $2030^{15}$. Alzheimer's disease is the most common cause for dementia. It rarely occurs under 60 years and, if it does, is often associated with specific genetic mutations. The incidence is age-related and the disease is more common in women. Dominantly inherited mutations do not play an important role in older women, although a common polymorphism in the gene that encodes apolipoprotein E increases risk, more so for women than men. The onset of Alzheimer's disease is insidious, with decrease in episodic memory, e.g. poor recall of recent events, verbal fluency and naming. It often coexists with vascular change and may be improved by better vascular function.

With aging, the incidence of all cancers is expected to increase ${ }^{16}$. For women, the most important cancers are breast, colon, endometrial, ovarian and lung cancer; the latter is the leading cause of cancer mortality in many countries. Possible prevention of these cancers by lifestyle changes and appropriate screening gains more importance after menopause ${ }^{17,18}$. Breast cancer is a more common cause of death than CVD prior to menopause. Conversely, treatment for cancer often accelerates the menopause, with subsequent impact on both quality of life, the presence of chronic disease and also reproductive function.

\section{METABOLIC EFFECTS, OBESITY AND DIABETES MELLITUS}

Obesity has emerged as a global health issue, affecting women in both developed and developing countries. The prevalence of obesity (defined as a BMI $\geq 30 \mathrm{~kg} / \mathrm{m}^{2}$ ) is greater in women than in men $^{19}$. Obesity makes a key contribution to the pathogenesis of diabetes mellitus, cardiovascular 
disease, dementia, some cancers (endometrial, breast and colon), depression, sexual dysfunction, urinary incontinence, and musculoskeletal disorders, especially osteoarthritis ${ }^{20-25}$.

\section{Obesity prevalence in women}

In $2008,14 \%$ of the global female population (300 million women) were obese ${ }^{26}$. The highest rates of obesity in women have been reported for the Americas (29\%), the Eastern Mediterranean (24\%) and Europe (23\%), and lowest for South East Asia $(3 \%)^{26}$.

Obesity is greater in women than in men, except in higher income countries ${ }^{26}$, and is inversely associated with poorer education and urbanization ${ }^{27,28}$. The global pandemic of obesity has been attributed to "the passive overconsumption of energy ${ }^{29}$. Other factors predictive of obesity in women at midlife include marriage at an early age, high parity, a family history of obesity, shift work, sleep deprivation, depression and some anti-psychotic medications ${ }^{28,30,31}$. The relationship between depression and type 2 diabetes is bidirectional ${ }^{32}$.

Central adiposity is strongly associated with an increase in risk of insulin resistance and the subsequent development of type 2 diabetes, and greater waist circumference is associated ${ }^{33}$ with increased mortality for women with BMIs between 20 and $50 \mathrm{~kg} / \mathrm{m}^{2}$. However, for predicting insulin resistance, the measurements of waist circumference and BMI have been found to be interchangeable, in that the more overweight/obese a person is, determined by either waist circumference or BMI, the greater the degree of insulin resistance ${ }^{34}$.

\section{Obesity and menopause}

Although women frequently report weight gain at midlife, studies across different populations have consistently shown that weight gain is primarily influenced by age, not menopause $\mathrm{e}^{35,36}$. The abrupt decline in estrogen at menopause is characterized by increased abdominal subcutaneous and visceral fat without commensurate change in physical activity or total body weight ${ }^{37}$. The result is a transition from a gynoid to an android pattern of fat distribution and an increase in total body fat ${ }^{38,39}$. This menopause-associated change in body composition is seen across ethnicities and in non-obese as well as obese women ${ }^{38}$. The accumulation of abdominal fat in postmenopausal women is a critical factor in the development of insulin resistance, which in turn is a major risk factor for progression to type 2 diabetes. Furthermore, abdominal weight gain after menopause is associated with the development of a more adverse lipid profile, with an increase in low density lipoprotein cholesterol and a decrease in the ratio of total cholesterol to high density lipoprotein (HDL) cholesterol ${ }^{37}$. Hence, the associations between abdominal weight gain and insulin resistance, and other age-related conditions in postmenopausal women, namely CVD, dementia ${ }^{40}$ and breast cancer ${ }^{41}$.

There is a complex, and incompletely understood, relationship between sex hormone binding globulin (SHBG), obesity and insulin resistance in women. Low SHBG is seen in obese men and women, is inversely associated with insulin resistance and is an independent predictor for the development of type 2 diabetes ${ }^{42}$. The inverse relationship between SHBG and insulin resistance is independent of 
endogenous estrogen and androgen levels and is, at least in part, independent of BMI in postmenopausal women ${ }^{43}$. Low SHBG is associated with liver fat accumulation which most likely explains the link between low SHBG, insulin resistance and type 2 diabetes ${ }^{44}$.

With central weight gain at menopause, there is also a decline in the production of adiponectin, an adipokine produced by fat. Serum adiponectin levels are low in clinical conditions associated with cardiovascular disease, insulin resistance and the metabolic syndrome ${ }^{45}$. Metformin, a drug widely used for the treatment of type 2 diabetes, stimulates this pathway ${ }^{46}$. As a result, metformin induces fatty acid oxidation, suppresses expression of lipogenic enzymes, and enhances insulin sensitivity.

\section{Prevention of obesity and insulin resistance}

The primary prevention of obesity resides in an appropriate balance between energy intake and expenditure $^{47}$. Public health policies to prevent obesity have raised a range of ethical issues which are beyond the scope of this review ${ }^{48}$. Interventions to treat obesity include physical activity, caloriecontrolled diet, pharmacotherapy or bariatric surgery. Complementary and alternative treatments such as acupuncture, yoga, and herbal supplements may also aid in weight loss. These have been recently reviewed $^{49}$. Most randomized, controlled trials have shown that menopausal hormone therapy (MHT) is associated with a reduction in central adiposity and an increase in insulin sensitivity ${ }^{50-52}$. In the Women's Health Initiative (WHI) intervention trials, both conjugated equine estrogen (CEE) alone and CEE plus medroxyprogesterone acetate (MPA) were associated with a reduction in risk for the development of type 2 diabetes compared with placebo (hazard ratio (HR) $0.86,95 \%$ confidence interval (CI) $0.76-0.98, p=0.02$; HR $0.81,95 \%$ CI $0.70-0.94, p=0.005$, respectively) ${ }^{5}$. This benefit did not persist after hormone therapy ceased.

Metformin therapy does not treat obesity, but prevents the progression of impaired glucose intolerance to type 2 diabetes ${ }^{53}$. Metformin also results in favorable lipoprotein effects, being independent of adiponectin, BMI, and insulin resistance ${ }^{53}$. Although metformin therapy has been observed to be slightly less effective in preventing type 2 diabetes than diet and exercise in randomized, controlled trials, long-term adherence to modified diets and exercise regimens outside the trial setting remains a challenge ${ }^{54}$. In summary, obesity is an increasing global health and economic burden ${ }^{55}$. This is reflected in the doubling of the number of people with type 2 diabetes over the past 30 years $^{56}$. Women in lower socioeconomic groups are more likely to become obese and to develop type 2 diabetes. The menopausal transition does not directly contribute to weight gain but rather to body fat redistribution, with more deposition in the abdomen. These changes increase the vulnerability to insulin resistance, glucose intolerance and type 2 diabetes. The most effective intervention for obesity is lifestyle modification.

Health-care providers should take every opportunity to prescribe dietary modification and physical activity, and women in the menopausal transition are ideal candidates to begin preventative measures. MHT may ameliorate fat redistribution and provide some protection against type 2 
diabetes, but should not be prescribed solely for this purpose. Metformin should be considered for women with impaired glucose tolerance to prevent the progression to type 2 diabetes.

\section{CARDIOVASCULAR DISEASES}

CVD, particularly CHD, is the leading cause of death in women in the developed world. The incidence increases at an annual rate which is greater than in men once menopause occurs. This suggests that protective factors in premenopausal women are lost at the time of menopause; the major candidate for this protective effect is estrogen.

Screening for CVD at regular intervals after menopause is extremely important. This includes measurement of blood pressure, lipids and perhaps inflammatory markers, BMI, and ascertainment of lifestyle factors such as activity level and smoking status. In addition, a family history of heart disease and stroke is important. In the future, we are likely to have genetic markers for risk assessment of CVD. At present, we have risk assessment tools which calculate the 10-year risk of a myocardial infarction based on gender and race for individuals aged 40-79 years. The main risk calculators used are the Framingham model, and a new one from the American Heart Association ${ }^{57}$. The latter is also used as part of the algorithm to decide about initiating statin therapy. The main components of these risk models are age, sex, race, total cholesterol, HDL cholesterol, systolic blood pressure, treatment for high blood pressure, diabetes and smoking status. Low-risk individuals have a 10-year risk of sustaining an event of $<7.5 \%$.

Interventions to reduce the risk of CVD after menopause include smoking cessation, weight control through diet and exercise, aggressive treatment of elevated blood pressure, and therapies directed at elevated cholesterol and thrombosis risks. The American Heart Association has outlined diet and lifestyle recommendations to reduce CVD, resulting in better population health, based on a variety of prospective studies ${ }^{58,59}$. In the PREMIER trial, 10-year CHD risk was calculated to be reduced by $12-$ $14 \%$ by lifestyle intervention which was considered to be 'substantial ${ }^{100}$. A recent Swedish study also confirmed that lifestyle interventions are cost-effective ${ }^{61}$.

The paradigm for the primary prevention of CHD in women through drug therapy stems primarily from intervention trials conducted in men, with the assumption that the outcome data in men are generalizable to women. However, data over the past decade have accumulated to refute this assumption. The prevailing belief is that statins reduce CHD events and all-cause mortality under primary and secondary prevention conditions in women and men. However, careful examination and meta-analyses of randomized, controlled trial (RCT) data do not provide clear evidence that statins reduce $\mathrm{CHD}$ events or all-cause mortality in women under primary prevention conditions.

Conclusions have been erroneously drawn from meta-analyses that combine secondary prevention trials with primary prevention trials and outcome data from men with data from women. For example, the Heart Protection Study, conducted predominantly in men (75\%) with only $15 \%$ of the cohort without vascular disease when randomized, was a secondary prevention trial that has driven much of the meta-analytic results that conclude that statins significantly reduce CHD in women under primary 
Table 1 Comparison of hormone replacement therapy, lipid lowering therapy and aspirin in the primary prevention of coronary heart disease and all-cause mortality in women. Data are given as relative risks $(95 \%$ confidence intervals)

\begin{tabular}{|c|c|c|c|c|}
\hline \multirow[b]{2}{*}{ Outcome } & \multicolumn{2}{|c|}{ Hormone therapy } & \multirow{2}{*}{$\begin{array}{c}\text { Lipid-lowering } \\
\text { therapy }\end{array}$} & \multirow[b]{2}{*}{ Aspirin } \\
\hline & Younger women* & Older women* & & \\
\hline Coronary heart & $0.68(0.48-0.96)^{67}$ & $1.03(0.91-1.16)^{67}$ & $0.87(0.69-1.09)^{64}$ & $1.01(0.84-1.21)^{70}$ \\
\hline \multirow[t]{2}{*}{ disease } & & & $0.95(0.78-1.16)^{65}$ & $0.91(0.80-1.03)^{71}$ \\
\hline & & & $0.79(0.56-1.13)^{66}$ & \\
\hline All-cause & $0.61(0.39-0.95)^{68}$ & $1.03(0.90-1.18)^{68}$ & $0.95(0.62-1.46)^{64}$ & $0.94(0.74-1.19)^{70}$ \\
\hline \multirow[t]{2}{*}{ mortality } & $0.72(0.62-0.82)^{69}$ & & $0.96(0.81-1.13)^{65}$ & $0.95(0.85-1.06)^{71}$ \\
\hline & & & $0.91(0.76-1.08)^{66}$ & \\
\hline
\end{tabular}

*, Younger women: < 60 years old and/or < 10 years since menopause when randomized; Older women: > 60 years old and/or > 10 years since menopause when randomized

prevention conditions. Careful examination of the source trials used in meta-analyses clearly shows that statins do not statistically significantly reduce CHD in women under primary prevention conditions $^{62,63}$.

In truly sex-specific meta-analyses that separate primary prevention trials from secondary prevention trials, statins do not show a clearly demonstrable statistical reduction in CHD in women ${ }^{64-66}$. Importantly, total mortality is not influenced by statin therapy used in women under primary prevention conditions (Table 1). The conclusions from these meta-analyses are supported by two primary prevention trials that included the largest cohorts of women, the Management of Elevated Cholesterol in the Primary Prevention Group of Adult Japanese (MEGA) trial in which 5356 women were followed for more than 5 years, and the Justification for the Use of Statins in Prevention: An Intervention Trial Evaluating Rosuvastatin (JUPITER) in 6801 women $^{62,63}$. While the latter trial has been heralded as showing that statins statistically significantly reduce CHD in women under primary prevention conditions, close examination of the data do not clearly support this conclusion ${ }^{62,63}$. The primary CVD endpoint in JUPITER was a composite of non-fatal MI, non-fatal stroke, or confirmed death resulting from cardiovascular causes (hard endpoints) as well as the occurrence of arterial revascularization or hospitalization for unstable angina pectoris (soft endpoints, which are a result of medical decisions). While men seemed to benefit, in women only the soft endpoints (revascularizations and hospitalizations) were significantly reduced with statin therapy and clearly drove the primary endpoint to statistical significance since none of the hard endpoints in the women differed significantly $(p>0.10)^{62,63}$. All-cause mortality was not statistically different between the statin and placebo arms in women $(p=0.12)$ or men $(p=0.08)$. Including JUPITER in meta-analyses along with other primary prevention trials does not alter the conclusion that statin therapy does not demonstrably reduce CHD events and has a null effect on all-cause mortality in primary prevention in women $^{62,63}$. In conclusion, for primary CHD prevention there is no clear evidence that statins reduce events or all-cause mortality in women. 
The sex-specific effects are similar for aspirin ${ }^{62,63,70}$. In meta-analyses of primary CHD prevention trials, aspirin significantly reduced MI by approximately $32 \%$, with a null effect on stroke in men, whereas, in women, aspirin had a null effect on MI but significantly reduced ischemic stroke by approximately $17 \%^{62,63}$. In women and men, aspirin therapy has a null effect on all-cause mortality under primary CHD prevention conditions. Consistent with statin therapy, the null effect of aspirin therapy on CHD extends to high-risk women with diabetes mellitus without a history of CVD. In the Japanese Primary Prevention of Atherosclerosis with Aspirin for Diabetes (JPAD) trial, the largest randomized, controlled trial of aspirin therapy and primary CHD prevention in individuals aged 30 85 years with type 2 diabetes mellitus (1152 women), the effect of aspirin therapy on CHD was null relative to placebo (relative risk (RR) $0.88,95 \%$ CI $0.53-1.44$ ) after a median treatment of 4.4 years ${ }^{62,63}$. The consistency across individual primary CHD prevention trials and sex-specific metaanalyses of primary prevention trials shows no evidence that aspirin therapy relative to placebo reduces CHD events or all-cause mortality in women.

Over the last decade, cumulated data from RCTs of MHT clearly demonstrate two distinct populations of women who respond differentially to MHT according to timing of MHT initiation relative to age and time since menopause ${ }^{62,63}$. Specifically, CHD events and all-cause mortality benefits occur when MHT is initiated in younger women $(<60$ years old) in close proximity to menopause $(<10$ years since menopause) and a null and possible adverse effect occurs when initiated in older women $(\geq 60$ years old) remote from menopause (> 20 years since menopause) ${ }^{62,63}$. These data have been reviewed extensively and conclusions from previous data have been confirmed by the latest compendium of MHT trial data from the WHI for all-cause mortality and CHD in women treated with unopposed estrogen ${ }^{5}$. The cumulative data conclusively show that, when initiated in women who are $<60$ years of age and/or within 10 years of menopause, MHT statistically significantly reduces CHD and total mortality ${ }^{62,63}$. These results have been validated in the Danish Osteoporosis Prevention Study (DOPS) conducted in women who were on average 7 months since menopause when randomized to MHT of long duration, 10 years of randomized therapy and 16 years of total follow-up ${ }^{72}$. The cumulative MHT randomized trial data initiated in younger women contrast to lipid-lowering and aspirin therapy in the primary prevention of CHD and, most importantly, in the reduction of all-cause mortality in women under primary prevention conditions (Table 1).

As with men, hypertension in women is the single, most important, treatable risk factor for stroke. Stroke risk increases continuously above $115 / 75 \mathrm{mmHg}$ with CVD risk doubling with each increment of $20 / 10 \mathrm{mmHg}^{73}$. With reduction of blood pressure, the risk of stroke is reduced by between 30 and $40 \%$, MI risk is reduced by $20-25 \%$ and heart failure is reduced by $50 \%$. The use of statin therapy in women in the primary prevention of stroke is less clear than that in men. Unlike the CHD data reviewed above, there are no published meta-analyses examining the effect of statins in the primary prevention of stroke in women. However, in a sex-stratified meta-analysis of secondary prevention trials (few participants with previous history of stroke), statins had no significant benefit on stroke (RR 0.92; 95\% CI 0.76-1.10) and all-cause mortality (RR 0.82; 95\% CI 0.76-1.13) in women ${ }^{74}$. On 
the other hand, statins may increase the risk for hemorrhagic stroke ${ }^{62,63}$. In contrast, aspirin significantly reduces ischemic stroke by approximately $17 \%$, but non-significantly increases hemorrhagic stroke by $24 \%$ relative to placebo in women ${ }^{62,63}$. Conversely, in women on average 64 years of age, MHT non-significantly increases ischemic stroke and reduces hemorrhagic stroke (18\% for CEE + MPA and 36\% for CEE) in relation to placebo. All of these foregoing events are rare, 5-11 events per 10000 women per year of MHT. Importantly, the risk of stroke is statistically nonsignificant and rare in women who initiate MHT when $<60$ years of age. The WHI showed that there are five additional strokes per 10000 women per year of CEE + MPA therapy when initiated in women $<60$ years of age and even lower for CEE therapy, and two fewer strokes per 10000 women per year of CEE therapy ${ }^{62,63}$. DOPS is consistent with these and other RCT findings for no increase in stroke risk when oral $17 \beta$-estradiol plus sequential norethisterone acetate or unopposed $17 \beta$-estradiol was used $^{62,63}$.

In conclusion, the risk of stroke from MHT is rare and of the same magnitude as seen with other medications such as statins and aspirin used in the prevention of CHD in women. When initiated in women $<60$ years old and/or $<10$ years since menopause, the benefits of MHT outweigh the risks, as MHT statistically significantly reduces CHD and all-cause mortality, two important outcomes not demonstrably proven to be reduced with statin and aspirin therapy, but each of which carry similar risks as $\mathrm{MHT}^{62,63}$, when used for the primary prevention of CHD in women.

\section{BONE EFFECTS (OSTEOPOROSIS, FRACTURES AND CHRONIC ARTHRITIS)}

Osteoporosis is defined as a systemic skeletal condition of deteriorating bone strength, resulting in fractures. The most common osteoporosis-related fractures are those of the vertebrae, hip, wrist, pelvis, sacrum, ribs, sternum, clavicle and humerus. All osteoporotic fractures are important in terms of disability and pain ${ }^{75}$ and are associated with increased morbidity and mortality ${ }^{76}$. Osteoporosisrelated fractures are common and will affect at least a third of women above the age of 50 years ${ }^{12}$. Osteoporosis affects an estimated 75 million people in Europe, the USA and Japan but, in view of increased life expectancy, it is estimated to increase by $240 \%$ by $2050^{77}$. It is estimated that more than 2 million osteoporosis-related fractures occurred in the USA during 2005 at a cost of $\$ 19$ billion. Hip fractures accounted for $72 \%$ of $\operatorname{costs}^{78}$.

Bone strength is closely linked to bone remodeling, a process that removes old bone (resorption) and replaces with new bone (formation) in women and men; age-related bone loss amounts to a loss of $1 \%$ per year. Menopause-related estrogen insufficiency results in additional bone resorption with additional bone loss for about 5 years.

\section{Strategies for the prevention of osteoporosis-related fractures}

Lifestyle and diet should be a mainstay strategy for preserving bone mass after menopause. Tobacco and excessive alcohol use are bone-toxic and should be avoided. Inactivity increases bone resorption. Moderate daily weight-bearing exercise increases bone formation and should be encouraged. 
Medication such as the use of glucocorticoids increases risk of fracture and should be used at the lowest effective dose for the shortest period of time. Falls should be prevented by sensible footwear, non-slippery floor surfaces and the avoidance of medication such as tranquilizers.

\section{Diet and supplementation}

A well-balanced diet is essential to maintain the protein matrix of bone. A low BMI increases the risk of fracture ${ }^{79}$. Postmenopausal women need a dietary reference intake (DRI) of $1200 \mathrm{mg}$ of elemental calcium $^{80}$. Supplemental calcium should be restricted to cover the shortfall between dietary intake and the DRI. Higher doses may be associated with cardiovascular harm $^{81}$ as well as renal calculi. Vitamin D is essential for calcium absorption. About $60 \%$ of older patients may have inadequate levels of vitamin D because of age-related skin changes and inadequate sunlight exposure. The Institute of Medicine in the USA recommends a DRI of 600 IU for women aged 51-70 years and 800 IU after age 70. Vitamin D supplementation has been shown to independently lower the risk of falling in elderly patients ${ }^{82}$.

\section{Pharmacological interventions for prevention}

The onset of menopause presents an ideal opportunity to assess risk of osteoporosis and associated fractures. This can be done using known risk factors and measuring bone density by dual-energy $\mathrm{X}$ ray absorptiometry. An integrated model such as FRAX (http://www.shef.ac.uk,2014) can predict the 10-year probability of fracture. The threshold for pharmacological intervention in the USA is advised as a 10 -year risk of hip fracture of $5 \%$ or of $20 \%$ for any osteoporotic fracture. A balance must be made between relying only on lifestyle measures and the need for pharmacological intervention, with the goal of preventing the morbidity and mortality of osteoporotic fractures.

In this section, we are not addressing agents for the treatment of established osteoporosis as defined by a $T$-score of $<-2.5$ or the presence of existing fragility fractures.

\section{Agents inhibiting resorption}

Use of MHT

It has been known for many years that menopause-associated bone loss can be prevented by the use of MHT in a dose-dependent way. Results of the WHI study presented the first evidence in a large RCT that MHT or estrogen alone reduces the risk of all osteoporosis-related fractures, even in patients at low risk of fracture ${ }^{83}$. Based on the initial results of the WHI, it was concluded that, when considering the negative effects of MHT on other disease outcomes, there was no net benefit ${ }^{84,85}$. This conclusion is challenged in view of reanalysis of the WHI data ${ }^{86,87}$. The initiation of MHT before the age of 60 or within 10 years after menopause (window of opportunity) poses very little risk ${ }^{88}$. A recent statement by the world's leading menopause societies stated that MHT is effective and appropriate for the prevention of osteoporosis-related fractures when initiated in the window of opportunity. The 
recommendation does not limit the duration of use as long as it confirms with treatment goals and individualized safety factors ${ }^{89}$.

Breast cancer is the main safety concern regarding the length of therapy, but this seems to be limited to the use of certain progestogens. The risk can be reduced by the use of more natural progestogens or bazedoxifene (BZA) to oppose the effect of estrogen on the endometrium ${ }^{90}$. It should be noted that the only evidence proving the fracture efficacy of MHT is for CEE at a dose of $0.625 \mathrm{mg}$ daily. MHT is especially useful in the younger patient with osteopenia. Most other bone-specific therapies lack proof of efficacy in this category.

\section{Selective estrogen receptor modulators}

Selective estrogen receptor modulators (SERMs) are a complex group of synthetic molecules that mimic the beneficial effects of estrogen on bone and lipids, without stimulating the estrogen receptors in breast and endometrium. Raloxifene $60 \mathrm{mg}$ daily reduces bone loss associated with the menopause but there is no evidence of fracture protection in the primary analysis of osteopenic women, although, in patients with established osteoporosis, the risk of vertebral fracture is reduced by $34-51 \%$ without any effect on non-vertebral fractures ${ }^{91}$. Raloxifene reduces the risk of invasive estrogen receptorpositive breast cancer by $76 \%^{92}$. Unlike estrogen, raloxifene does not treat the vasomotor symptoms of menopause and may in fact cause hot flushes.

BZA is a SERM approved for the prevention of vertebral fractures ${ }^{93,94}$. Although its fractureprotective effect is broadly comparable to that of raloxifene, BZA offers superior endometrial protection compared to all other SERMs. This enables BZA to be paired with CEE to avoid the negative effects of CEE on the endometrium and the breast, while still treating the vasomotor symptoms associated with menopause, as well as maintaining vaginal health and bone mineral density ${ }^{95}$.

\section{Bisphosphonates}

Bisphosphonates are potent inhibitors of bone turnover and are effective agents for the prevention of fractures in established osteoporosis. They have a limited role in prevention in younger women with osteopenia alone for the following reasons:

- Alendronate has been shown to be ineffective in the prevention of fractures in patients with a $T$-score $>-2.5$ without any fractures ${ }^{96}$;

- The duration of therapy for prevention in the younger patient is expected to be more than 5 years. The use of bisphosphonates for more than 5 years may be associated with atypical femur fractures. Atypical femur fractures occur in the subtrochanteric region of the femur shaft, after minimal trauma, are often preceded by prodromal pain or a stress fracture and often occur bilaterally. An X-ray of an atypical femur fracture features a simple transverse or oblique fracture of the femur and diffuse cortical thickening of the proximal femoral shaft ${ }^{97}$. Although the causal relationship between the bisphosphonates and atypical fragility fractures has not been proven conclusively ${ }^{98}$, it has 
been suggested that alendronate be stopped after 5 years for a drug-free holiday in patients at low risk of fracture ${ }^{99}$.

- Osteonecrosis of the jaw is a condition described as an area of exposed alveolar bone in the mandible or maxilla for more than 8 weeks in a patient currently or previously treated with bisphosphonates. Osteonecrosis of the jaw is mostly confined to therapeutic interventions for oncological indications when doses are higher than approved for fracture.

\section{Denosumab}

Denosumab, a human monoclonal antibody to the receptor activator of nuclear factor- $\mathrm{B}$ ligand (RANKL), at a dose of $60 \mathrm{mg}$ subcutaneously 6-monthly, significantly reduces the risk of vertebral, non-vertebral and hip fractures in patients with established osteoporosis. It has a limited role to play in prevention in the younger osteopenic woman. Denosumab may also have adverse immunological effects $^{100}$.

\section{SKIN, CARTILAGE AND OTHER CONNECTIVE TISSUES}

Menopausal loss of estrogen is associated with a loss of connective tissue in the dermis of the skin, in the medial arterial layers and intervertebral disc as well as articular cartilage. Osteoarthritis can be particularly debilitating and is a major cause of morbidity for many women after menopause. Osteoarthritis will affect 59.4 million people in the USA by 2020; for knee osteoarthritis alone, the incidence is 240 per 100000 person-years ${ }^{101}$. Osteoarthritis has been thought to be second only to $\mathrm{CHD}$ as a cause of work disability in individuals over age 50. The economic consequences of osteoarthritis in the USA are $\$ 100$ billion annually and will increase by $25 \%$ by $2020^{102}$. While osteoarthritis is more common in men than women before menopause, it is higher in women after menopause. The identification of women with a family history of arthritis or those who are beginning to have stiff joints and immobility at the onset of menopause is important and may allow for interventions such as physical therapy, weight loss, physical exercise and anti-inflammatory agents ${ }^{103}$. There are some data suggesting that estrogen may have a role in improving or decreasing the risk of osteoarthritis ${ }^{104}$.

\section{DEMENTIA, COGNITIVE DECLINE AND DEPRESSION}

Dementia, even more than cancer, is the principal health concern of many older adults. During the natural menopause transition and early postmenopause, some women notice forgetfulness or other cognitive symptoms, which can evoke disquieting concerns of mental decline. During the menopause transition, there may in fact be modest reductions in aspects of attention ${ }^{105}$, but natural menopause per $s e$ does not appear to lead to poorer memory ${ }^{106}$. For many cognitive skills, subtle decline begins much earlier in adult life ${ }^{107}$, and there is no evidence for a change in trajectory around the time of menopause. Premature menopause is less well studied ${ }^{108}$, and surgical menopause at a relatively young age is linked to heightened risk of cognitive impairment or dementia ${ }^{109,110}$. 
Cognitive aging is conceptually separate from pathological processes that underlie specific forms of dementia. Alzheimer's disease, by far the most common cause of dementia, is characterized by neuritic plaques and neurofibrillary tangles ${ }^{111}$. A conspicuous feature is the aggregation and propagation of aberrant, misfolded proteins, such as $\beta$-amyloid. At autopsy, Alzheimer changes are often found together with other pathologies that themselves cause dementia ${ }^{112}$. These include infarction (vascular dementia), Lewy bodies (dementia with Lewy bodies) and TDP-43 inclusions (frontotemporal dementia). A patient may develop dementia when the plaque and tangle burden is relatively modest, if another pathology is present at the same time ${ }^{112}$.

Because most dementia is due to Alzheimer pathology in isolation or in combination with other pathologies ${ }^{112}$, strategies to maintain cognitive health focus on Alzheimer's disease prevention. Biochemical and metabolic biomarkers of Alzheimer's disease may precede dementia symptoms by decades $^{113}$, and prevention of mild cognitive impairment and late-life dementia may therefore require interventions well in advance of old age. The three general approaches are to (1) improve brain health, (2) increase cognitive reserve, and (3) reduce Alzheimer pathology ${ }^{114}$.

\section{Improving brain health}

A larger burden of Alzheimer pathology can be tolerated before the threshold for clinical symptoms is reached in an otherwise healthy brain. CVD is an attractive target for preventive interventions. The pathologies of CVD and Alzheimer's disease often occur together ${ }^{112}$, and they share common risk factors ${ }^{115}$. These include hypertension, diabetes, hyperlipidemia, midlife obesity, and cigarette smoking. Cardiovascular improvement might impact Alzheimer pathology directly (through effects on oxidative stress or inflammatory cytokines, for example), but the primary effect is probably due to reductions in intracranial atherosclerosis and small infarcts ${ }^{112,116}$. Strategies to enhance cardiovascular health would be expected to delay the onset of not only vascular dementia but also dementia triggered by accumulating Alzheimer pathology.

\section{Increasing cognitive reserve}

Cognitive reserve implies greater capacity, efficiency or redundancy in terms of brain areas and neural pathways used when a cognitive task is performed ${ }^{117}$. There is consistent evidence that people of greater intelligence, higher educational achievement, and cognitively demanding occupations are at lower risk for Alzheimer's disease. Mentally stimulating leisure activities and social engagement might also reduce risk, presumably in part through similar mechanisms. There is no evidence that supports any particular mental activity over another.

\section{Reducing Alzheimer pathology through physical activity}

A robust literature links aerobic exercise to cognitive maintenance and reducing Alzheimer risk ${ }^{118,119}$. The estimated Alzheimer risk reduction is about $28 \%{ }^{119}$. In animal models ${ }^{120}$ and in humans ${ }^{121}$, 
physical exercise reduces $\beta$-amyloid deposition in the brain. In healthy adults, exercise also increases the volume of the hippocampus ${ }^{122}$, a brain region critically important to memory. Other exercise effects may be mediated through neurotropic factors induced by exercise ${ }^{123-125}$.

\section{Reducing Alzheimer pathology: estrogen therapy}

Estrogens may affect Alzheimer pathology. After ovariectomy, estradiol reduces $\beta$-amyloid deposition in transgenic mice that develop Alzheimer-like pathology ${ }^{126}$. Other effects on neural plasticity, neurogenesis, oxidative stress and cerebral metabolism could boost brain reserve ${ }^{127-129}$. However, effects of estrogen-containing hormone therapy on dementia risk are controversial. Findings from the Women's Health Initiative Memory Study indicate that CEE/MPA in women over age 65 doubles the risk of dementia ${ }^{130}$, although changes with CEE alone were not significant. To the contrary, hormone therapy used after surgical menopause ${ }^{109}$, by younger postmenopausal women (but not older postmenopausal women) ${ }^{131}$, and during midlife (but not during late life) ${ }^{132,133}$ is associated with lower Alzheimer risk. One possibility is that estrogen effects on Alzheimer risk are modified by age or temporal proximity to menopause ${ }^{134}$. It is not known whether WHI findings in women aged 65 and older generalize to women in their early fifties - women most likely to consider hormone therapy for moderate to severe vasomotor symptoms. It is also unknown whether unrecognized confounding in observational studies of younger postmenopausal women has led to invalid inferences on risk reduction. For cognitive outcomes in the absence of dementia, the evidence is now more secure. Convincing clinical trial data indicate that MHT does not appreciably affect cognitive abilities of relatively healthy postmenopausal women ${ }^{135,136}$. Of concern, women with premature menopause are poorly represented in research to date.

\section{Depression}

Women are twice as likely as men to develop depression ${ }^{137}$. The menopausal transition may be a time of increased vulnerability, but depression risk does not appear to be elevated in the late postmenopause $^{138}$. Depression is strongly associated with Alzheimer's disease risk ${ }^{139,140}$, but the association may not be causal. Some instances of adult-onset depression may be triggered by neurofibrillary tangle formation in serotonergic and noradrenergic brainstem nuclei well before

cognitive symptoms begin to emerge ${ }^{141,142}$; these neurotransmitter systems are implicated in depression. Inflammation and oxidative stress ${ }^{139}$ may predispose both to depression and Alzheimer's disease. Cortisol is implicated more directly. Levels of this stress hormone are increased in depression. Higher levels may reduce brain reserve through deleterious effects on the hippocampus and possibly may contribute to $\beta$-amyloid accumulation as well ${ }^{143,144}$.

\section{Strategies to combat cognitive decline and dementia}

Current evidence, unfortunately, does not strongly endorse any particular risk-reduction strategy ${ }^{119}$ but does support some approaches over others. Brain health should be bolstered through amelioration of 
cardiovascular risk factors; cognitive reserve should be increased through mentally stimulating activities associated with occupation, leisure activities and social engagement; and Alzheimer pathology should be attacked through regular aerobic physical activity ${ }^{114}$. Depression should be recognized and treated, and women in their sixties or older should not start hormone therapy. The lack of certainty regarding effective strategies highlights the need for well-designed efficacy and pragmatic trials.

\section{CANCER RISK}

In 2012, there were 6.7 million cases of cancer in women world-wide out of a total of 14.1 million $^{145}$. The total number is expected to rise to 24 million in 2035. Breast cancer is the most common cancer (1.67 million new cases in 2012) followed by colorectal (614 000), lung (583 000), cervix (528 000), stomach (320 000), endometrium (320 000), and ovary (239 000). Breast cancer alone contributes $25.2 \%$ of the cases, and the top three contribute more than $43 \%$ of all cancer cases. Cancer rates are 1.8 times higher in more developed than less developed countries, with the exception of cervical cancer. The country with the highest cancer rate in women is Denmark (328.8/100 000) followed by the USA (297.4/100 000) and the Republic of Korea (293.6/100 000) ${ }^{145}$. The age-specific incidence of various cancers varies by region of the world. For breast cancer, the incidence increases after menopause, whereas in Asia it is increased before or at menopause. Mortality rates for cancer also vary by type and region of the world, but mostly increase with age.

\section{Screening for cancer}

Genetic factors are thought to contribute significantly to the risk of various cancers. Although some polymorphisms of interest have been identified, mass screening for specific mutations is impractical at the present, but may be more commonplace in the future. Among the more than 20 mutations identified for breast cancer, each only explains a small percentage of cases. For example, mutations in BRCA1 and BRCA2 are associated with only $5 \%$ of breast cancer cases ${ }^{146}$.

Incidence and mortality can be, at least partially, controlled by screening programs. Perhaps the best example of this is for cervical cancer. Cervical cancer can be almost eradicated by implementation of screening through Pap smears or possibly HPV detection. A drastic reduction in cervical cancer incidence and mortality has been observed in all countries where systematic screening has been adopted. In addition, HPV vaccination is now available and is also associated with a decrease in all the diseases associated with the HPV infection (cervical, anal and oral cancers). For developing countries, the WHO recommends that Pap smears be performed commencing at the age of 30 years, every 10 years.

Breast cancer mortality has significantly decreased in countries where a national screening program is available. Screening is recommended by performing mammography (biannually in most countries) between 50 and 74 years of age. In the case of high-risk women, screening can begin earlier in the life and be annual. Magnetic resonance imaging is reserved for women who are carriers of BRCA1/2 
mutations, based on testing because of breast cancer in the family, or for difficult-to-read mammography.

Different strategies are proposed for colon cancer. Fecal occult blood testing (FOBT) is the most widely used screening test for colorectal cancers and the only screening test currently recommended by the European Union. As colorectal cancers only bleed intermittently, FOBTs have to be repeated either each year or every other year. Although the sensitivity for testing is low, a Cochrane metaanalysis quantified a relative reduction in mortality of $16 \%{ }^{147}$. Colonoscopy is the best diagnostic tool but has not been rigorously evaluated in randomized trials; virtual colonoscopy is a new technique that has not yet found its place in practice.

There have been no specific screening tests validated for detection of endometrial, ovarian, lung and other cancers, although several are in clinical use. It is anticipated, however, that more specific molecular profiling for certain cancers will be available in the future. Annual history and physical examinations are still important in the process of screening for cancer and a family history of certain cancers may warrant more specific diagnostic testing. A strong history of smoking may warrant lung imaging.

Smoking, alcohol, high BMI, dietary factors and physical activity are the main modifiable risk factors. Controlling these factors could decrease the incidence of cancer as reported previously ${ }^{148}$. It has been estimated that one-third of the approximately 572000 cancer deaths in the USA can be attributed to diet and physical activity habits, and another third due to use of tobacco products ${ }^{149}$. In the European cohort study (EPIC), compliance with lifestyle strategies, using a scoring system, resulted in risk reduction in participants in the range of $16 \%$ for breast cancer, $27 \%$ for colorectal cancer, $14 \%$ for lung cancer, and $23 \%$ for endometrial cancer ${ }^{150}$. Overall, $12.6 \%$ (95\% CI 3.6-21.4\%) of all cancers could have been prevented in the whole study population.

Cessation of smoking and reduction in alcohol consumption ( $<15 \mathrm{~g} /$ day $)$ are important. Specific recommendations for constituents of diet (such as lower fat, increased fiber and decreased meats and specifically red meat) and exercise have been studied in clinical trials and are specified in the American Cancer Society Guidelines ${ }^{151}$. Exercise is usually advised to be of a 'vigorous' nature for at least $2-3 \mathrm{~h} /$ week. There is inconclusive evidence for benefit from various types of supplements such as vitamins and minerals.

Use of MHT should not be thought of as a strategy to decrease cancer risk. However, older observational studies have suggested a decrease in cancer mortality with MHT; total cancer was decreased by $20 \%$ in the $50-59$-year-old group with CEE in the $\mathrm{WHI}^{5}$ and, again in the WHI, CEE alone showed a decrease in breast and total mortality after 10 years ${ }^{152}$. There is also strong evidence for a protective effect for colon cancer with MHT. On the other hand, breast cancer may be increased with prolonged use of standard doses of estrogen in combination with certain progestogens; estrogen alone either decreases the risk or increases it marginally with very prolonged use (10-15 years) ${ }^{90}$. 
In conclusion, screening and risk assessment (eventually with genetic and novel molecular tools) should be implemented widely. Lifestyle modification with persistent adherence to diet, exercise and avoidance of certain exposures (including tobacco and alcohol) will decrease the risk of cancer.

\section{CONSIDERATION OF MHT FOR PREVENTION: CONCERNS OVER THE WHI}

\section{ANALYSIS}

Despite misgivings about a possible increase in the risk of breast cancer, by the end of the 20th century it was commonly believed that the relief of menopausal symptoms, coupled with the beneficial effects of MHT on the risk of CHD, osteoporotic fractures, and cancer of the large bowel justified the use of MHT.

In 2002, the initial findings reported from the $\mathrm{WHI}^{83}$, a clinical trial of CEE/MPA versus placebo, radically changed that perception. The trial was terminated after a median of 5.2 years of follow-up because it purportedly established, surprisingly, that CEE/MPA does not reduce the risk of CHD, but actually increases it; that CEE/MPA does indeed cause breast cancer; and that a 'global index' which synthesized the risks of CHD, breast cancer, stroke, pulmonary embolism, colorectal cancer, endometrial cancer, hip fracture, and all-cause mortality indicated that, overall, the risks outweighed the benefits.

Considerable publicity was given to the WHI findings and, from 2002 onward, the use of MHT rapidly declined world-wide. In the USA, for example, MHT use declined by $66 \%{ }^{153}$. That decline was accentuated in 2005, when a WHI clinical trial of CEE versus placebo ${ }^{154}$ was terminated after 7.2 years of follow-up because of an increased risk of stroke. In that trial, however, robust statistical evidence suggested that CEE does not increase the risk of breast cancer, and more borderline evidence even suggested that CEE may actually reduce the risk.

Over the years, further WHI studies were published ${ }^{5}$, and in 2013 the overall effects of CEE/MPA and of CEE after a total of 13 years of follow-up were reported ${ }^{5}$. In that report, risks for the outcomes at issue were estimated for the periods before the trials ended (the 'intervention' phases), and for the periods after the trials ended (the 'postintervention' phases), when the women were 'unblinded', and free to use or not use MHT. The overall conclusion in this last report was that MHT should not be used for chronic disease prevention. This was largely driven by data from the group receiving CEE/MPA (including all ages) and largely influenced by the perception of an increased risk for breast cancer.

Recently, the validity of the WHI findings ${ }^{155}$ has been evaluated by applying generally accepted epidemiological criteria of causation (or prevention) ${ }^{156-158}$ to the evidence. The conclusion of that review is that it is by no means established that MHT should not be used for disease prevention. First, the 'global index' was not a validated tool, and it was not a legitimate reason for terminating the CEE/MPA trial: CHD, breast cancer, stroke, pulmonary embolism, colorectal cancer, endometrial cancer, and hip fracture are dissimilar clinical and pathological entities, with different age and ethnic distributions, environmental and genetic determinants and dosage and duration effects. Statistically, 
while it may be possible to synthesize the risks of such a wide range of dissimilar outcomes into a single estimate, in clinical or epidemiological terms, using that single estimate to evaluate overall benefit versus risk is not valid.

The 'global index' was also biased. The risk of hip fractures and vertebral fractures was significantly reduced. Yet, while both fractures were originally included in the 'global index', for unexplained reasons, vertebral fractures were removed. The effect of the removal was to bias the 'global index' and make it more seemingly adverse. Also, the WHI did not employ routine X-ray detection and thus missed the asymptomatic radiological fractures. The high rates of discontinuation in the active treatment arm (42\%) and cross-over to active treatment in the placebo arm (10.7\%) further diluted the effect of MHT on fracture reduction and beg the question on the use of intention-to-treat analysis. A consideration of risk versus benefit would be different depending on the population under study. Such a consideration would be different, for example, for women with benign breast disease, a family history of breast cancer, hypertension, hyperlipidemia, osteoporosis, and so on; the applicability of an overall global index to any individual woman is questionable.

Second, mainly because of uterine bleeding, the respective 'unblinding' rates among the CEE/MPA and placebo recipients were $44.4 \%$ and $6.4 \%{ }^{83}$. Inevitably, the considerably higher rate among the CEE/MPA users resulted in the selectively biased detection of otherwise 'clinically silent' breast cancers. In addition, the significantly increased risk of breast cancer was borderline and dependent on its definition as a 'primary outcome'. In the original protocol, breast cancer was specified as a 'secondary outcome'. Had that definition not been changed, the association would not have been statistically significant, and it could have been due to chance.

The evidence that the increased risk of breast cancer among CEE/MPA users was biased was further supported by the WHI findings among the CEE recipients (where unblinding was only $2 \%$ ). In that trial, statistically robust and unbiased evidence suggested that CEE does not increase the risk of breast cancer; and it was statistically significantly decreased among adherent women and in 10-year followup data ${ }^{152}$. The unbiased findings for CEE raise the possibility that the biased findings for CEE/MPA may have been spurious. Moreover, when adjustments to the primary data were carried out for confounding variables, the entire group did show a statistical increase in breast cancer ${ }^{159}$. These data also showed that the increase in risk only applied to women who were prior users of MHT ${ }^{159}$. Third, the originally reported, significantly increased risk of CHD in CEE/MPA users declined as follow-up continued and, as time progressed, the findings for CHD were inconsistent and not statistically significant. The initially reported increased risk of CHD at 5.2 years ${ }^{83}$ was no longer significantly increased after 5.6 years ${ }^{5}$ and, at 13 years, it was no longer present at all. It is likely that the differential 'unblinding' rates in the CEE/MPA and placebo recipients resulted in the biased detection of otherwise 'clinically silent' CHD in CEE/MPA users. Consequently, a reduced risk of CHD was not excluded in the WHI study.

In short, the three original reasons for terminating the CEE/MPA trial, an increased risk of breast cancer, an increased risk of CHD, and an adverse 'global index' were not valid. Moreover, the best 
evidence suggests that the use of unopposed estrogen does not increase the risk of breast cancer and may even reduce it.

On the adverse side of the equation, all that has been established or confirmed in the WHI studies is that CEE/MPA (and presumably CEE as well) increases the risk of pulmonary embolism and, possibly, of stroke, although statistical rigor was not applied to this analysis. And it is by no means clear that these adverse effects counterbalance the well-established reduced risks of osteoporotic fractures and colorectal cancer in MHT users.

Under the extreme assumption that all increased risks identified in the WHI study were causal, and that all risk reductions were protective, absolute risks (incidence rates in non-exposed women subtracted from the rates in exposed women) were estimated ${ }^{5}$. The incidence rates attributable to exposure ranged from -7 to 11 per 10000 women per year. That is, even if the limitations of the WHI study are set aside for the moment, under the 'worst case' or 'best case' assumptions, the changes in incidence attributable to MHT were very uncommon events.

Finally, in the WHI study only oral CEE and MPA were studied. The products currently in use have different biological effects and are often prescribed in lower doses and by different routes. Therefore, the WHI recommendation that MHT should not be used for chronic disease prevention is not defensible. The misrepresentation and over-interpretation of the limited evidence, nevertheless, have resulted in considerable harm to the health and well-being of menopausal women.

\section{MHT AS A POSSIBLE PREVENTION THERAPY AFTER MENOPAUSE}

The statistical and interpretation concerns of the hormone trials of the WHI do not allow us to conclude that MHT does not have a role in prevention as noted above. Moreover, yet to be considered in the analysis is that the risk-benefit analysis is quite different for younger women as reviewed under the CVD section. The abrupt cessation of MHT by most women after the initial reports from the WHI, because of fear of harm, has been associated with an increase in osteoporotic fractures ${ }^{160,161}$; a mathematical calculation has also suggested there may be more CHD deaths in women who have had a hysterectomy and have not used estrogen ${ }^{162}$.

Women close to menopause or in the age range of 50-59 years are the most appropriate candidates for the initiation of MHT; it is not appropriate to initiate MHT in older women for prevention. In this younger age group of generally healthy women, there is clear evidence for cardiovascular benefit ${ }^{163}$. The largely quoted perception, that even women aged 50-59 years receiving combination therapy (CEE/MPA) have an increased risk of CHD, was not a statistically significant finding. Because the analysis of younger women in the WHI was a subgroup analysis, it has been stated that we cannot rely on these data. However, these data, particularly for CEE alone, are completely consistent with older observational data and similar to another RCT, DOPS, with 16 years of follow-up ${ }^{72}$ and a metaanalysis of 23 RCTs in women < 60 years old or within 10 years of menopause, as reviewed in the CVD section. A Bayesian meta-analysis analyzing observational and RCT data (although debated on statistical grounds) is also consistent in showing a reduction in mortality in younger women with the 
use of $\mathrm{MHT}^{69}$. Although ischemic stroke risk may be observed in younger women (including users of oral contraceptives), the degree of risk is of borderline significance and the absolute risk in younger women is rare. In the 13-year follow-up data, in the 50-59-year-old groups receiving CEE or CEE/MPA, neither group showed a statistical increase in stroke in the intervention or follow-up periods $^{5}$.

The timing hypothesis for the initiation of MHT posits that a critical window of about 6 years from the time of menopause exists for a protective effect for CHD. The recent data from ELITE has confirmed this hypothesis in that women within 6 years of menopause had a reduction in carotid intima-media thickness with oral estradiol $1 \mathrm{mg}$ over time, whereas women more than 10 years from menopause did not show this effect ${ }^{164}$. The timing hypothesis may also be relevant for maintenance of cognitive function and reduction in Alzheimer's disease risk, although our current data are insufficient to draw any conclusions.

The strength of the findings noted above is considered to be more appropriately evaluated by longerterm data with a follow-up of at least 10 years. The 10- and 13-year follow-up data of the 50-59-yearold women receiving CEE in the WHI trial showed statistically significant reductions for MI and the global index ${ }^{5,165}$, and DOPS showed 16-year follow-up data for a protective effect for cardiovascular outcomes and mortality ${ }^{72}$. These data also support the cost-effective analysis showing that, when MHT is initiated early and continued for 15-30 years, the quality-adjusted life-years increase by 1.5 years at a cost of $\$ 2400$ per quality-adjusted life-year, which is considered very cost-effective ${ }^{166}$ and is similar to another analysis in symptomatic women ${ }^{167}$.

Regarding types of MHT, the data on protection are less convincing with the addition of a progestogen (MPA in the WHI). The fixed combination of CEE and MPA in the WHI only showed a trend to benefit in the younger age group. Nevertheless, in DOPS, the addition of sequential norethindrone acetate in the women with a uterus did not appear to attenuate outcomes. Until more data are available on differences in formulations, the addition of progestogens in MHT with the goal of preventing CHD and mortality should be carried out with caution and be individualized. Synthetic progestogens have also been implicated in the long-term breast cancer risk with MHT.

We also do not have adequate information on the types of estrogen for the purpose of prevention. While certain risks of MHT, namely deep vein thrombosis and ischemic stroke (although rare in younger women) may be reduced or eliminated by the use of transdermal estrogen, we do not have evidence to date on the cardiovascular benefits discussed above. Differences in each woman's own biology, genetics and susceptibility to risk factors suggest that different types of MHT will be needed. Thus, there is probably no ideal MHT regimen, and no specific regimen can be endorsed at this time. The decision to use MHT as a strategy for prevention in younger women after menopause is not a straightforward decision. However, as discussed above, there are no other proven therapies, apart from lifestyle measures, that can be instituted. In the younger woman who has menopausal symptoms, the decision to treat is clear. Similarly, in younger women with a high risk for osteoporotic fracture, a strong argument can be made for the initiation of MHT which should be beneficial. In other women, 
other issues such as quality of life and risk factors need to be considered more carefully. Yet MHT may be considered as part of an armamentarium for prevention in selected younger women in this category.

\section{SUMMARY OF PREVENTION STRATEGIES}

Assessment of risks for chronic diseases assumes a great importance at the onset of menopause. This includes history, physical examination and analysis of certain established markers of risk, and, in the future, molecular and genetic markers as well. The first 10 years after menopause are an important window for intervention.

For all women, lifestyle measures (diet and exercise), control of body weight, mentally stimulating activity and regular screening for cancer should be carried out. As part of this armamentarium, MHT should be considered, particularly in symptomatic women. Beyond this, the identification of specific risks (e.g. osteoporosis) may warrant more specific prevention therapy.

\section{CONCLUSION/SUMMATION}

As life expectancy increases, women around the world will be experiencing more years of life after menopause. Improving the quality of women's lives after menopause should be the goal for all who provide care to women. Chronic diseases as outlined here begin to occur around the age of 60 years; thus, there is an important window of about 10 years from the time of menopause to make a significant impact on prevention, and the onset of menopause heralds this important opportunity. In each of the diseases listed above, there is good evidence to support lifestyle changes (diet and exercise) and cessation of smoking and excessive alcohol consumption to decrease the incidence of these diseases. In addition, there is compelling evidence to suggest that MHT may be considered as part of this overall strategy.

Conflict of interest Professor S. R. Davis has received a Research Fellowship Grant no. 1041853 from NHMRC Australia, consultancy fees from Trimel Pharmaceuticals Canada, and unrestricted grant support from Lawley Pharmaceuticals Australia and Besins Healthcare; Dr T. J. de Villiers has received honoraria for lectures for Bayer, Abbott and Pfizer and for acting as a member of Advisory Boards for Merck and Amgen, and travel assistance from Pfizer; Professor A. Gompel has received honoraria for lectures for Viropharma and funding to a non-profit organization for consultancy work for Behring, Richter, and Shire; Dr W. J. Mack and Professor H. N. Hodis have received Research grants from the National Institutes of Health; Professor S. Shapiro has received honoraria for acting as a member of Advisory Boards for Bayer Schering and Merck; Professor R. J. Baber has received honoraria for lectures for Abbott Pharmaceuticals. Professors R. A. Lobo, V. W. Henderson and M. A. Lumsden report no conflicts of interest. 


\section{References}

1. Gold EB, Bromberger J, Crawford S, et al. Factors associated with age at natural menopause in a multiethnic sample of midlife women. Am J Epidemiol 2001;153:865-74

2. Dratva J, Gomez RF, Schindler C. Is age at menopause increasing across Europe? Results on age at menopause and determinants from two population-based studies. Menopause 2009;16:385-94

3. Kriplani A, Banerjee K. An overview of age of onset of menopause in northern India. Maturitas 2005;52:199-204

4. Manson JE, Tosteson H, Ridker PM, et al. The primary prevention of myocardial infarction. $N$ Engl J Med 1992;326:1406-16

5. Manson JE, Chlebowski RT, Stefanick ML, et al. Menopausal hormone therapy and health outcomes during the intervention and extended poststopping phases of the Women's Health Initiative randomized trials. JAMA 2013;310:1353-68

6. Kim C, Cleary PA, Cowie CC, et al. Effect of glycemic treatment and microvascular complications on menopause in women with type 1 diabetes in the Diabetes Control and Complications Trial/Epidemiology of Diabetes Interventions and Complications (DCCT/EDIC) Cohort. Diabetes Care 2014;37:701-8

7. Go AS, Mozaffarian D, Roger VL, et al. Heart disease and stroke statistics - 2014 update: a report from the American Heart Association. Circulation 2014;129:e28-292

8. Ebong IA, Watson KE, Goff DC Jr, et al. Age at menopause and incident heart failure: the Multi-Ethnic Study of Atherosclerosis. Menopause 2014;21:585-91

9. Wellons M, Ouyang P, Schreiner PJ, Herrington DM, Vaidya D. Early menopause predicts future coronary heart disease and stroke: the Multi-Ethnic Study of Atherosclerosis. Menopause 2012;19:1081-7

10. Tom SE, Cooper R, Wallace RB, Guralnik JM. Type and timing of menopause and later life mortality among women in the Iowa Established Populations for the Epidemiological Study of the Elderly (EPESE) cohort. J Womens Health (Larchmt) 2012;21:10-16

11. Compston J. How to manage osteoporosis after the menopause. Best Pract Res Clin Rheumatol 2005;19:1007-19

12. Johnell O, Kanis J. Epidemiology of osteoporotic fractures. Osteoporos Int 2005;16(Suppl 2):S3-7

13. Pirro M, Fabbriciani G, Leli C, et al. High weight or body mass index increase the risk of vertebral fractures in postmenopausal osteoporotic women. J Bone Miner Metab 2010;28:88-93

14. Briggs AM, Greig AM, Wark JD. The vertebral fracture cascade in osteoporosis: a review of aetiopathogenesis. Osteoporos Int 2007;18:575-84

15. Reitz C, Brayne C, Mayeux R. Epidemiology of Alzheimer disease. Nat Rev Neurol 2011;7:137-52

16. Hosseini MS, Arab M, Nemati HB, et al. Age-specific incidence rate change at breast cancer and its different histopathologic subtypes in Iran and Western countries. Pak J Med Sci 2013;29:1354-7

17. Zhang Y, Liu H, Yang S, Zhang J, Qian L, Chen X. Overweight, obesity and endometrial cancer risk: results from a systematic review and meta-analysis. Int J Biol Markers 2014;29:e21-9

18. Lee H, Li JY, Fan JH, et al. Risk factors for breast cancer among Chinese women: a 10-year nationwide multicenter cross-sectional study. J Epidemiol 2014;24:67-76

19. World Health Organization. Obesity and overweight. Fact sheet No. 311, May 2012. Available from: http://www.who.int/mediacentre/factsheets/fs311/en/ 
20. Pace G, Silvestri V, Guala L, Vicentini C. Body mass index, urinary incontinence, and female sexual dysfunction: how they affect female postmenopausal health. Menopause 2009;16:1188-92

21. Connolly BS, Barnett C, Vogt KN, Li T, Stone J, Boyd NF. A meta-analysis of published literature on waistto-hip ratio and risk of breast cancer. Nutr Cancer 2002;44:127-38

22. Renehan AG, Tyson M, Egger M, Heller RF, Zwahlen M. Body-mass index and incidence of cancer: a systematic review and meta-analysis of prospective observational studies. Lancet 2008;371:569-78

23. Istvan J, Zavela K, Weidner G. Body weight and psychological distress in NHANES I. Int J Obes Relat Metab Disord 1992;16:999-1003

24. Cicuttini FM, Baker JR, Spector TD. The association of obesity with osteoarthritis of the hand and knee in women: a twin study. J Rheumatol 1996;23:1221-6

25. Botlero R, Davis SR, Urquhart DM, Shortreed S, Bell RJ. Age-specific prevalence of, and factors associated with, different types of urinary incontinence in community-dwelling Australian women assessed with a validated questionnaire. Maturitas 2009;62:134-9

26. Global Health Observatory. Obesity. Geneva: World Health Organization, 2014. Available at: http://www.who.mt/gho/ncd/risk_factors/obesity

27. Jacoby E, Goldstein J, Lopez A, Nunez E, Lopez T. Social class, family, and life-style factors associated with overweight and obesity among adults in Peruvian cities. Prev Med 2003;37:396-405

28. Hajian-Tilaki KO, Heidari B. Prevalence of obesity, central obesity and the associated factors in urban population aged 20-70 years, in the north of Iran: a population-based study and regression approach. Obes Rev 2007;8:3-10

29. Swinburn BA, Sacks G, Hall KD, et al. The global obesity pandemic: shaped by global drivers and local environments. Lancet 2011;378:804-14

30. Fonken LK, Workman JL, Walton JC, et al. Light at night increases body mass by shifting the time of food intake. Proc Natl Acad Sci USA 2010;107:18664-9

31. Sutin AR, Zonderman AB. Depressive symptoms are associated with weight gain among women. Psychol Med 2012;42:2351-60

32. Pan A, Lucas M, Sun Q, et al. Bidirectional association between depression and type 2 diabetes mellitus in women. Arch Intern Med 2010;170:1884-91

33. Cerhan JR, Moore SC, Jacobs EJ, et al. A pooled analysis of waist circumference and mortality in 650,000 adults. Mayo Clin Proc 2014;89:335-45

34. Farin HM, Abbasi F, Reaven GM. Body mass index and waist circumference both contribute to differences in insulin-mediated glucose disposal in nondiabetic adults. Am J Clin Nutr 2006;83:47-51

35. Sternfeld B, Wang H, Quesenberry CP Jr, et al. Physical activity and changes in weight and waist circumference in midlife women: findings from the Study of Women's Health Across the Nation. Am J Epidemiol 2004;160:912-22

36. Guthrie JR, Dennerstein L, Dudley EC. Weight gain and the menopause: a 5-year prospective study. Climacteric 1999;2:205-11

37. Franklin RM, Ploutz-Snyder L, Kanaley JA. Longitudinal changes in abdominal fat distribution with menopause. Metabolism 2009;58:311-15

38. Abdulnour J, Doucet E, Brochu M, et al. The effect of the menopausal transition on body composition and cardiometabolic risk factors: a Montreal-Ottawa New Emerging Team group study. Menopause 2012;19:760-7 
39. Ho SC, Wu S, Chan SG, Sham A. Menopausal transition and changes of body composition: a prospective study in Chinese perimenopausal women. Int J Obes (Lond) 2010;34:1265-74

40. Han TS, van Leep EM, Serdeel JC, Lean ME. Waist circumference action levels in the identification of cardiovascular risk factors: prevalence in a random sample. BMJ 1995;311:1401-5

41. Cust AE, Stocks T, Lukanova A, et al. The influence of overweight and insulin resistance on breast cancer risk and tumour stage at diagnosis: a prospective study. Breast Cancer Res Treat 2009;113:567-76

42. Ding EL, Song Y, Manson JE, et al. Sex hormone-binding globulin and risk of type 2 diabetes in women and men. N Engl J Med 2009;361:1152-63

43. Davis SR, Robinson PJ, Moufarege A, Bell RJ. The contribution of SHBG to the variation in HOMA-IR is not dependent on endogenous oestrogen or androgen levels in postmenopausal women. Clin Endocrinol (Oxf) $2012 ; 77: 541-7$

44. Flechtner-Mors M, Schick A, Oeztuerk S, et al. Associations of fatty liver disease and other factors affecting serum SHBG concentrations: a population based study on 1657 subjects. Horm Metab Res 2014;46:287-93

45. Inoue M, Maehata E, Yano M, Taniyama M, Suzuki S. Correlation between the adiponectin-leptin ratio and parameters of insulin resistance in patients with type 2 diabetes. Metabolism 2005;54:281-6

46. Zhou G, Myers R, Li Y, et al. Role of AMP-activated protein kinase in mechanism of metformin action. $J$ Clin Invest 2001;108:1167-74

47. Dubnov-Raz G, Berry EM. The dietary treatment of obesity. Med Clin N Am 2011;95:939-52

48. Buchanan D. Ethical standards to guide the development of obesity policies and programs. Comment on 'Ethical agreement and disagreement about obesity prevention policy in the United States'. Int J Health Policy Manag 2013;1:313-15

49. Davis SR, Castelo-Branco C, Chedraui P, et al. Understanding weight gain at menopause. Climacteric 2012;15:419-29

50. Sorensen MB, Rosenfalck AM, Hojgaard L, Ottesen B. Obesity and sarcopenia after menopause are reversed by sex hormone replacement therapy. Obes Res 2001;9:622-6

51. Yuksel H, Odabasi AR, Demircan S, et al. Effects of oral continuous 17beta-estradiol plus norethisterone acetate replacement therapy on abdominal subcutaneous fat, serum leptin levels and body composition. Gynecol Endocrinol 2006;22:381-7

52. Davis SR, Walker KZ, Strauss BJ. Effects of estradiol with and without testosterone on body composition and relationships with lipids in postmenopausal women. Menopause 2000;7:395-401

53. Goldberg R, Temprosa M, Otvos J, et al. Lifestyle and metformin treatment favorably influence lipoprotein subfraction distribution in the Diabetes Prevention Program. J Clin Endocrinol Metab 2013;98:3989-98

54. Merlotti C, Morabito A, Pontiroli AE. Prevention of type 2 diabetes; a systematic review and meta-analysis of different intervention strategies. Diabetes Obes Metab 2014 Jan 29. Epub ahead of print

55. Lee CM, Colagiuri R, Magliano DJ, et al. The cost of diabetes in adults in Australia. Diabetes Res Clin Pract 2013;99:385-90

56. Chen L, Magliano DJ, Zimmet PZ. The worldwide epidemiology of type 2 diabetes mellitus - present and future perspectives. Nat Rev Endocrinol 2012;8:228-36

57. American Heart Association. https: www.heart.org/gglRisk/

58. Lichtenstein AH, Appel LJ, Brands M, et al. Diet and lifestyle recommendations revision 2006: a scientific statement from the American Heart Association Nutrition Committee. Circulation 2006;114:82-96 
59. Spring B, Ockene JK, Gidding SS, et al. Better population health through behavior change in adults: a call to action. Circulation 2013;128:2169-76

60. Maruthur NM, Wang N-Y, Appel LJ. Lifestyle interventions reduce coronary artery disease risk. Results from the PREMIER trial. Circulation 2009;119:2026-31

61. Saha S, Carlsson KS, Gerdtham U-G, et al. Are lifestyle interventions in primary care cost-effective? An analysis based on a Markov model, differences-in-differences approach and the Swedish Bjorknas study. PLOS One 2013;8, e80672:1-10

62. Hodis HN, Mack WJ. The timing hypothesis and hormone replacement therapy: a paradigm shift in the primary prevention of coronary heart disease in women. 1. Comparison of therapeutic efficacy. J Am Geriatr Soc 2013;61:1005-10

63. Hodis HN, Mack WJ. The timing hypothesis and hormone replacement therapy: a paradigm shift in the primary prevention of coronary heart disease in women. 2. Comparative risks. J Am Geriatr Soc 2013;61:101118

64. Walsh JME, Pignone M. Drug treatment of hyperlipidemia in women. JAMA 2004;291:2243-52

65. Petretta M, Costanzo P, Perrone-Filardi P, Chiariello M. Impact of gender in primary prevention of coronary heart disease with stain therapy: a meta-analysis. Int J Cardiol 2010;138:25-31

66. Brugts JJ, Yetgin T, Hoeks SE, et al. The benefits of statins in people without established cardiovascular disease but with cardiovascular risk factors: meta-analysis of randomised controlled trials. BMJ 2009;338:b2376 67. Salpeter SR, Walsh JME, Greyber E, Salpeter EE. Coronary heart disease events associated with hormone therapy in younger and older women: a meta-analysis. J Gen Intern Med 2006;21:363-6

68. Salpeter SR, Walsh JME, Greybe, E, Ormiston TM, Salpeter EE. Mortality associated with hormone replacement therapy in younger and older women: a meta-analysis. J Gen Intern Med 2004;19:791-804 69. Salpeter SR, Cheng J, Thabane L, Buckley NS, Salpeter EE. Bayesian meta-analysis of hormone therapy and mortality in younger postmenopausal women. Am J Med 2009;122:1016-22

70. Berger JS, Roncaglioni MC, Avanzini F, et al. Aspirin for the primary prevention of cardiovascular events in women and men: a sex-specific meta-analysis of randomized controlled trials. JAMA 2006;295:306-13

71. Ridker PM, Cook NR, Lee IM, et al. A randomized trial of low-dose aspirin in the primary prevention of cardiovascular disease in women. N Engl J Med 2005;352:1293-304

72. Schierbeck LL, Rejnmark L, Tofteng CL, et al. Effect of hormone replacement therapy on cardiovascular events in recently postmenopausal women: randomized trial. BMJ 2012;345:e6409

73. Lawes CMM, Bennett DA, Feigin VL, Rodgers A. Blood pressure and stroke: an overview of published reviews. Stroke 2004;35:1024-33

74. Gutierrez J, Ramirez G, Rundek T, Sacco RL. Statin therapy in the prevention of recurrent cardiovascular events: a sex-based meta-analysis. Arch Intern Med 2012;172:909-19

75. Reginster JY, Seeman E, De Vernejoul MC, et al.; Strontium ranelate reduces the risk of nonvertebral fractures in postmenopausal women with osteoporosis: Treatment of Peripheral Osteoporosis (TROPOS) study.

J Clin Endocrinol Metab 2005;90:2816-22

76. Cauley JA, Thompson DE, Ensrad KC, et al. Risk of mortality following clinical fractures. Osteoporos Int 2000;11:556-61

77. Gullberg B, Johnell O, Kanis JA. World-wide projections for hip fracture. Osteoporos Int 1977;7:407-13

78. Burge R, Dawson-Hughes B, Solomon DH, et al. Incidence and economic burden of osteoporosis-related fractures in the United States, 2005-2025. J Bone Miner Res 2007;22:465-75 
79. De Laet C, Kanis JA, Oden A, et al. Body mass index as a predictor of fracture risk: a meta-analysis.

Osteoporos Int 2005;16:1330-8

80. Institute of Medicine. website: www.iom.edu/Reports/2010/Dietary

81. Boland MJ, Avenell A, Baron JA, et al. Effect of calcium supplements on risk of myocardial infarction and cardiovascular events: meta-analysis. BMJ 2010;341:c3691

82. Bischoff-Ferrari HA, Dawson-Hughes B, Willett W, et al. Fall prevention by vitamin D treatment: a metaanalysis of randomized controlled trials. JAMA 2004;291:1999-2006

83. The Writing Group for the Women's Health Initiative Investigators. Risks and benefits of estrogen plus progestin in healthy postmenopausal women: principal results from the Women's Health Initiative randomized controlled trial. JAMA 2002;288:321-33

84. Jackson RD, Wactawski-Wende J, LaCroix AZ, et al. Effects of conjugated equine estrogen on risk of fractures and BMD in postmenopausal women with hysterectomy: results from the Women's Health Initiative randomized trial. J Bone Miner Res 2006;21:817-28

85. Cauley JA, Robbins J, Chen Z, et al. Effects of estrogen plus progestin on risk of fracture and bone mineral density: the Women's Health Initiative randomized trial. JAMA 2003;290:1729-38

86. De Villiers TJ. Individualized therapy for osteoporosis prevention and treatment in women under 60.

Climacteric 2009;12:210-12

87. De Villiers TJ, Stevenson J. The WHI: The effect of hormone replacement therapy on fracture prevention.

Climacteric 2012;15:263-6

88. Rossouw JE, Prentice RL, Manson JE, et al. Postmenopausal hormone therapy and risk of cardiovascular disease by age and years since menopause. JAMA 2007;7:1465-77

89. De Villiers TJ, Gass MLS, Haines CJ, et al. Global consensus statement on menopausal hormone therapy. Climacteric 2013;16:203-4

90. De Villiers TJ, Pines A, Panay N, et al. Updated 2013 International Menopause Society recommendations on menopausal hormone therapy and preventive strategies for midlife health. Climacteric 2013;16:316-37

91. Ettinger B, Black DM, Mitlak BH, et al.; Multiple Outcomes of Raloxifene Evaluation (MORE)

Investigators. Reduction of vertebral fracture risk in postmenopausal women with osteoporosis treated with raloxifene: results from a 3-year randomized clinical trial. JAMA 1999;282:637-45

92. Martino S, Cauley JA, Barrett-Connor E, et al. for CORE Investigators. Continuing outcomes relevant to Evista; breast cancer incidence in postmenopausal osteoporotic women in a randomized trial of raloxifene. $J$ Natl Cancer Inst 2004;96:1751-61

93. De Villiers TJ, Chines AA, Palacios S, et al. Safety and tolerability of bazedoxifene in postmenopausal women with osteoporosis: results of a 5-year, randomized, placebo-controlled phase 3 trial. Osteoporos Int 2011;22:567-76

94. De Villiers TJ. Bazedoxifene: a novel selective estrogen receptor modulator for postmenopausal osteoporosis. Climacteric 2010;13:210-18

95. Lindsay R, Gallagher JC, Kagan R, et al. Efficacy of tissue-selective estrogen complex of bazedoxifene/conjugated estrogens for osteoporosis prevention in at-risk postmenopausal women. Fertil Steril 2009;92:1045-52

96. Cummings SR, Black DM, Thompson DE, et al. Effect of alendronate on risk of fracture in women with low bone density but without vertebral fractures: results from the Fracture Intervention Trial. JAMA 1998;280:207782 
97. Lenart BA, Lorich DG, Lane JM. Atypical fractures of the femoral diaphysis in postmenopausal women taking alendronate. $N$ Engl J Med 2008;358:1304-6

98. Abrahamsen B, Eiken P, Eastell R. Subtrochanteric and diaphyseal femur fractures in patients treated with alendronate: a register-based national cohort study. J Bone Miner Res 2009;24:1095-102

99. Colon-Emeric C. Editorial. Ten vs five years of bisphosphonate treatment for osteoporosis. JAMA 2006;296:2968-9

100. Black DM, Delmas PD, Eastell R, et al.; HORIZON Pivotal Fracture Trial. Once-yearly zoledronic acid for treatment of postmenopausal osteoporosis. N Engl J Med 2007;356:1809-22

101. Oliveria SA, Felson DT, Reed JI, Cirillo PA, Walker AM. Incidence of symptomatic hand, hip and knee osteoarthritis among patients in a health maintenance organization. Arthritis Rheum 1995;38: 1134-41

102. Weinstein JN, Barmier JD. The Dartmouth Atlas of Musculoskeletal Health Care. Chicago: American Hospital Association Press, 2000

103. Arthritis Foundation, 2014. www.arthritis.org/conditions-treatments/disease-center/osteoarthritis

104. Tanko LB, Christiansen C, Karsdal MA. Potentials of estrogens in the prevention of osteoarthritis: what do we know and what questions are still pending? In Lobo RA, ed. Treatment of the Postmenopausal Woman.

Academic Press, 2007:393-401

105. Weber MT, Mapstone M, Staskiewicz J, Maki PM. Reconciling subjective memory complaints with objective memory performance in the menopausal transition. Menopause 2012;19:735-41

106. Henderson VW. Gonadal hormones and cognitive aging: a midlife perspective. Women's Health (Lond Engl) 2011;7:81-93

107. Salthouse TA. When does age-related cognitive decline begin? Neurobiol Aging 2009;30:507-14

108. Henderson VW, Sherwin BB. Surgical versus natural menopause: cognitive issues. Menopause 2007;14:572-9

109. Bove R, Secor E, Chibnik LB, et al. Age at surgical menopause influences cognitive decline and Alzheimer pathology in older women. Neurology 2014;82:222-9

110. Rocca WA, Bower JH, Ahlskog JE, et al. Increased risk of cognitive impairment or dementia in women who underwent oophorectomy before menopause. Neurology 2007;69:1074-83

111. Querfurth HW, LaFerla FM. Alzheimer's disease. N Engl J Med 2010;362:329-44

112. Schneider JA, Arvanitakis Z, Bang W, Bennett DA. Mixed brain pathologies account for most dementia cases in community-dwelling older persons. Neurology 2007;69:2197-204

113. Bateman RJ, Xiong C, Benzinger TL, et al. Clinical and biomarker changes in dominantly inherited Alzheimer's disease. N Engl J Med 2012;367:795-804

114. Henderson VW. Three midline strategies to prevent cognitive impairment due to Alzheimer's disease. Climacteric 2014 June 4. Epub ahead or print

115. Stampfer MJ. Cardiovascular disease and Alzheimer's disease: common links. J Intern Med 2006;260:21123

116. Dolan H, Crain B, Troncoso J, et al. Atherosclerosis, dementia, and Alzheimer disease in the Baltimore Longitudinal Study of Aging cohort. Ann Neurol 2010;68:231-40

117. Stern Y. Cognitive reserve in aging and Alzheimer's disease. Lancet Neurol 2012;11:1006-12

118. Sofi F, Valecchi D, Bacci D, et al. Physical activity and risk of cognitive decline: a meta-analysis of prospective studies. J Intern Med 2011;269:107-17 
119. Williams JW, Plassman BL, Burke J, et al. Preventing Alzheimer's Disease and Cognitive Decline.

Evidence Report/Technology Assessment Number 193. Department of Health and Human Services, Rockville, MD, 2010. AHRQ Publication No. 10-E005

120. Liu HL, Zhao G, Zhang H, Shi LD. Long-term treadmill exercise inhibits the progression of Alzheimer's disease-like neuropathology in the hippocampus of APP/PS1 transgenic mice. Behav Brain Res 2013;256:26172

121. Liang KY, Mintun MA, Fagan AM, et al. Exercise and Alzheimer's disease biomarkers in cognitively normal older adults. Ann Neurol 2010;68:311-18

122. Erickson KI, Voss MW, Prakash RS, et al. Exercise training increases size of hippocampus and improves memory. Proc Natl Acad Sci USA 2011;108:3017-22

123. Cotman CW, Berchtold NC, Christie LA. Exercise builds brain health: key roles of growth factor cascades and inflammation. Trends Neurosci 2007;30:464-72

124. Kobilo T, Liu QR, Gandhi K, et al. Running is the neurogenic and neurotrophic stimulus in environmental enrichment. Learning Memory 2011;18:605-9

125. Korol DL, Gold PE, Scavuzzo CJ. Use it and boost it with physical and mental activity. Hippocampus 2013;32:125-35

126. Vest RS, Pike CJ. Gender, sex steroid hormones, and Alzheimer's disease. Horm Behav 2013;63:301-7

127. Bailey ME, Wang AC, Hao J, et al. Interactive effects of age and estrogen on cortical neurons: implications for cognitive aging. Neuroscience 2011;191:148-58

128. Ding F, Yao J, Zhao L, et al. Ovariectomy induces a shift in fuel availability and metabolism in the hippocampus of the female transgenic model of familial Alzheimer's disease. PLoS One 2013;8:e59825

129. McClure RE, Barha CK, Galea LA. 17ß-Estradiol, but not estrone, increases the survival and activation of new neurons in the hippocampus in response to spatial memory in adult female rats. Horm Behav 2013;63:14457

130. Shumaker SA, Legault C, Rapp SR, et al. Estrogen plus progestin and the incidence of dementia and mild cognitive impairment in postmenopausal women: the Women's Health Initiative Memory Study (WHIMS).

JAMA 2003;289:2651-62

131. Henderson VW, Benke KS, Green RC, et al. Postmenopausal hormone therapy and Alzheimer's disease risk: interaction with age. J Neurol Neurosurg Psychiatry 2005;76:103-5

132. Shao H, Breitner JCS, Whitmer RA, et al. Hormone therapy and AD dementia: new findings from the Cache County study. Neurology 2012;79:1846-52

133. Whitmer RA, Quesenberry CP, Zhou J, Yaffe K. Timing of hormone therapy and dementia: the critical window theory revisited. Ann Neurol 2011;69:163-9

134. Resnick SM, Henderson VW. Hormone therapy and risk of Alzheimer disease: a critical time. JAMA 2002;288:2170-2

135. Asthana S, Gleason CE, Wharton W, et al. The Kronos Early Estrogen Prevention Study: results of the Cognitive \& Affective Sub-Study (KEEPS Cog). Menopause 2012;19:1364 (Abstr)

136. Henderson VW, Popat RA. Effects of endogenous and exogenous estrogen exposures in midlife and latelife women on episodic memory and executive functions. Neuroscience 2011;191:129-38

137. Weissman MM, Bland RC, Canino GJ, et al. Cross-national epidemiology of major depression and bipolar disorder. JAMA 1996;276:293-9 
138. Maki PM, Freeman EW, Greendale GA, et al. Summary of the National Institute on Aging-sponsored conference on depressive symptoms and cognitive complaints in the menopausal transition. Menopause 2010;17:815-22

139. Diniz BS, Butters MA, Albert SM, et al. Late-life depression and risk of vascular dementia and Alzheimer's disease: systematic review and meta-analysis of community-based cohort studies. Br J Psychiatry 2013;202:329-35

140. Ownby RL, Crocco E, Acevedo A, et al. Depression and risk for Alzheimer disease: systematic review, meta-analysis, and metaregression analysis. Arch Gen Psychiatry 2006;63:530-8

141. Braak H, Thal DR, Ghebremedhin E, Del Tredici K. Stages of the pathologic process in Alzheimer disease: age categories from 1 to 100 years. J Neuropathol Exp Neurol 2011;70:960-9

142. Grinberg LT, Rüb U, Ferretti RE, et al. The dorsal raphe nucleus shows phospho-tau neurofibrillary changes before the transentorhinal region in Alzheimer's disease. A precocious onset? Neuropathol Appl Neurobiol 2009;35:406-16

143. Byers AL, Yaffe K. Depression and risk of developing dementia. Nature Rev Neurol 2011;3:323-31

144. Green KN, Billings LM, Roozendaal B, et al. Glucocorticoids increase amyloid-beta and tau pathology in a mouse model of Alzheimer's disease. J Neurosci 2006;30:9047-56

145. Ferlay J, Soerjomataram I, Ervik M, et al. GLOBOCAN 2012 v 1.0, Cancer Incidence and Mortality World Wide: IARC Cancer Base No.11 (internet). Lyon, France: International Agency for Research on Cancer, 2013 146. Robson M, Offit K. Clinical practice. Management of an inherited predisposition to breast cancer. $N$ Engl J Med 2007;357:154-62

147. Hewitson P, Glasziou P, Irwig L, Towler B, Watson E. Screening for colorectal cancer using the faecal occult blood test. Hemoccult Cochrane Database Syst Rev 2007(1):CD001216

148. Gompel A, Baber RJ, de Villiers TJ, et al. Oncology in midlife and beyond. Climacteric 2013;16:522-35 149. World Cancer Research Fund/American Institute for Cancer Research. Food, Nutrition, Physical Activity, and the Prevention of Cancer: A Global Perspective. Washington DC: World Cancer Research Fund/American Institute for Cancer Research, 2007

150. Romaguera D, Vergnaud AC, Peeters PH, et al. Is concordance with World Cancer Research Fund/American Institute for Cancer Research guidelines for cancer prevention related to subsequent risk of cancer? Results from the EPIC study. Am J Clin Nutr 2012;96:150-63

151. Kushi LH, Doyle C, McCullough M, et al. and the American Cancer Society 2010 Nutrition and Physical Activity Guidelines Advisory Committee. American Cancer Society Guidelines on Nutrition and Physical Activity for Cancer Prevention: reducing the risk of cancer with healthy food choices and physical activity. $C A$ Cancer J Clin 2012;62:30-67

152. Anderson G. Conjugated equine estrogen and breast cancer incidence and mortality in postmenopausal women with hysterectomy: extended follow-up of the Women's Health Initiative randomised placebo-controlled trial. Lancet Oncol 2012;13:476-86

153. Hersh AL, Stefanick ML, Stafford RL. National use of menopausal hormone therapy: annual trends and response to recent evidence. JAMA 2004;291:47-53

154. The Women's Health Initiative Steering Committee. Effects of conjugated equine estrogen in postmenopausal women with hysterectomy: the Women's Health Initiative randomized controlled trial. JAMA 2004;291:1701-12 
155. Shapiro S. Bias in the evaluation of low-magnitude associations: an empirical perspective. Am J Epidemiol 2000;151:939-945

156. Hill AB. The environment and disease: association or causation? Proc R Soc Med 1965;58:295-300

157. Susser M. Causal Thinking in the Health Sciences. New York: Oxford University Press, 1979

158. Susser M. What is a cause and how do we know one? Am J Epidemiol 1991;133:635-48

159. Anderson GL, Chlebowski RT, Rossouw JE, et al. Prior hormone therapy and breast cancer risk in the Women's Health Initiative randomized trial of estrogen plus progestin. Maturitas 2006;55:103-15

160. Karim R, Dell RM, Greene DF, Mack WJ, Gallagher JC, Hodis HN. Hip fracture in postmenopausal women after cessation of hormone therapy: results from a prospective study in a large health management organization. Menopause 2011;18:1172-7

161. Islam S, Liu Q, Chines A, Helzner. Trend in incidence of osteoporosis-related fractures among 40- to 69year-old women: analysis of a large insurance claims database, 2000-2005. Menopause 2009;16:77-82 162. Sarrel PM, NjikeV, Vinante V, Katz DL. The mortality toll of estrogen avoidance: an analysis of excess deaths among hysterectomized women age 50 to 59. Am J Pub Health 2013;103:1583-8

163. Lobo RA. Where are we 10 years after the Women's Health Initiative? J Clin Endocrinol Metab 2013;98:1771-80

164. Hodis HN. ELITE - Does the trial outcome confirm or refute the timing hypothesis of hormone therapy? Presented at the14th World Congress on Menopause of the International Menopause Society, May 1-4, 2014, Cancun, Mexico

165. LaCroix AZ, Chlebowski RT, Manson JE, et al.; WHI Investigators. Health outcomes after stopping conjugated equine estrogens among postmenopausal women with prior hysterectomy: a randomized controlled trial. JAMA 2011;305:1305-14

166. Salpeter SR, Cheng J, Thabane L, Buckley NS, Salpeter EE. The cost-effectiveness of hormone therapy in younger and older postmenopausal women. Am J Med 2009;122:45-52

167. Lekander I, Borgström F, Ström O, et al. Cost-effectiveness of hormone therapy in the United States. $J$ Womens Health 2009;18:1669-77 